\title{
Bioatividade de óleos essenciais na germinação e no vigor em sementes de tomate
}

\author{
Luzirene Almeida ${ }^{1}$ \\ Maria da Conceição Sampaio Alves Teixeira ${ }^{1 \star}$ \\ Jesus Rodrigues Lemos ${ }^{2}$ \\ Mairla Nascimento de Lacerda ${ }^{1}$ \\ Taline Cunha Silva ${ }^{1}$ \\ ${ }^{1}$ Universidade Estadual do Piauí, Campus de Parnaíba \\ Avenida Nossa Senhora de Fátima, s/n, CEP 64.202-020, Parnaíba - PI, Brasil \\ ${ }^{2}$ Universidade Federal do Piauí, Parnaíba - PI, Brasil \\ * Autor para correspondência \\ ceicaotx@phb.uespi.br
}

\section{Resumo}

A alelopatia é o efeito de uma planta sobre outra por intermédio da produção de compostos químicos que são liberados no meio ambiente. Portanto, objetivou-se identificar os efeitos alelopáticos de extratos voláteis de óleos essenciais de colônia (Alpinia zerumbet (Pers.) B. L. Burtt. \& R. M. Sm.), goiaba (Psidium guajava L.) e nim (Azadirachta indica A. Juss) na germinação e no comprimento da raiz de plântulas de tomate (Lycopersicum esculentum). Os óleos foram extraídos das folhas de plantas adultas, por arraste a vapor de água. Foram utilizadas cinco concentrações de cada óleo $(0,0 ; 0,25 ; 0,50 ; 0,75$ e 1,0\%, v/v), em delineamento inteiramente casualizado, com quatro repetições de 25 sementes. Para o teste de germinação foram avaliados os parâmetros: porcentagem de germinação (G\%) e índice de velocidade de germinação (IVG). Para o crescimento inicial foram avaliados o comprimento da radícula (CR) e o comprimento da parte aérea (CPA). O óleo de colônia inibiu a germinação na concentração de $1 \%$, bem como reduziu o IVG; nas concentrações de $0,75 \%$ e $1 \%$ inibiu totalmente o comprimento radicular e o comprimento da parte aérea. Para o óleo de goiaba houve redução na germinação com o aumento das concentrações.

Palavras-chave: Efeitos tóxicos; Plantas medicinais

\section{Abstract}

Bioactivity of essential oils on the germination and vigor of tomato seeds. Allelopathy is the effect of one plant on another through the production of chemical compounds that are released into the environment. Therefore, the objective of this study was to identify the allelopathic effects of volatile extracts of essential oils of shell ginger (Alpinia zerumbet (Pers.) B. L. Burtt. \& R. M. Sm.), guava (Psidium guajava L.) and neem (Azadirachta indica A. Juss) on the germination and root length of tomato seedlings. The oils were extracted from the leaves of adult plants by steam distillation. Five concentrations of each oil were used $(0.0 ; 0.25 ; 0.50 ; 0.75 ;$ and $1.0 \%$, $\mathrm{v} / \mathrm{v})$ in a completely randomized design with four replicates of 25 seeds. For the germination test parameters, 
the following were evaluated: percentage of germination (G\%) and germination speed index (GSI). For initial growth, the length of the radicle and the length of the aerial part were evaluated. The oil of shell ginger inhibited germination at a concentration of $1 \%$, as well as reduced the GSI, and the $0.75 \%$ and $1 \%$ concentrations totally inhibited root length and the length of the aerial part. For the guava oil, there was a reduction in germination as the concentration increased.

Key words: Medicinal Plants; Toxic Effects

\section{Introdução}

A alelopatia é o efeito de uma planta sobre outra por intermédio da produção de compostos químicos que são liberados no meio ambiente (RICE, 1984). Esses compostos, chamados de aleloquímicos ou metabólitos secundários, estão presentes em todos os tecidos das plantas, tanto em órgãos vegetativos quanto em reprodutivos, sendo que ambos têm potencial para armazenar esses metabólitos (RIZVI et al., 1992; SOUZA et al., 2006).

A bioatividade dos aleloquímicos envolve estímulo ou inibição do desenvolvimento de outras espécies, quando esses compostos são liberados no meio ambiente, causam alterações morfológicas e metabólicas em espécies vizinhas, podendo afetar o crescimento, prejudicar o desenvolvimento normal e até mesmo inibir a germinação das sementes de outras espécies vegetais (REZENDE et al., 2003; FIORENZA et al., 2016).

Almeida (1991) enfatiza que as substâncias alelopáticas provocam redução da germinação, falta de vigor vegetativo ou morte das plântulas, amarelecimento ou clorose das folhas, redução do perfilhamento e atrofiamento ou deformação das raízes. Além disso, as substâncias aleloquímicas, quando liberadas no solo, podem interferir nas plantas superiores, afetando a germinação e provocando lesões durante o crescimento de raízes e meristemas, prejudicando o desenvolvimento da planta (GOMES et al., 2014).

Em contrapartida, essas substâncias podem desempenhar a função de proteção, prevenção na decomposição das sementes, redução da dormência, produção de gemas, além de influenciar nas relações com as demais plantas, microrganismos e insetos (PICCOLO et al., 2007). Muitas plantas medicinais demonstram atividades alelopáticas, pois os mesmos constituintes químicos responsáveis pelas atividades medicinais são ativos, influenciando positiva ou negativamente no crescimento de outras plantas (SOUZA et al., 2005). Essas plantas podem então apresentar-se como uma ferramenta alternativa no controle de plantas infestantes em cultivos agrícolas. Com isso, de acordo com Rosa et al. (2007), podem configurar como alternativa ecológica e reduzir agroquímicos, sendo utilizadas como bioherbicidas.

O efeito alelopático de óleos essenciais e de extratos de plantas já foi comprovado em alguns estudos e indica as potencialidades do uso dos metabólitos secundários presentes nas diversas espécies vegetais, tais como S. trilobata em tomate, cebola, rabanete e repolho (HERNÁNDEZ-ARO et al., 2016); Araucaria angustifolia em alface (SILVEIRA et al., 2014); Plectranthus barbatus em Amaranthus deflexus (LESSA et al., 2017); Pachyrhizus erosus L. em Euphorbia heterophylla e Bidens pilosa (BARBOSA et al., 2018); Anacardium occidentale em tomate e alface (MATIAS et al., 2017); picão preto (Bidens pilosa L.) em feijão comum (Phaseolos vulgaris L.) (COELHO et al., 2014).

Alpinia zerumbet (Pers.) B. L. Burtt. \& R. M. Sm. (Zingiberaceae), conhecida pelos nomes vulgares de colônia, paco-serosa, pacová e cuité-açu (LORENZI; SOUZA, 2001), vem merecendo atenção especial devido à sua relevância quanto às suas propriedades na medicina popular. O chá preparado com as folhas, flores ou raízes tem sido usado no tratamento caseiro da hipertensão, estomáticas, vermífugas, calmante e também como diurético (ALMEIDA, 1993; LARANJA et al., 1991; 1992).

Psidium guajava L. (Myrtaceae), conhecida como "goiabeira", possui atividade antimicrobiana, antimutagênica e atividade hipoglicêmica, entre outras (AMARAL et al., 2006; GONDIM et al., 2006). Na medicina popular é utilizada para cólicas, colite, diarreia, disenteria e dor de barriga (VENDRUSCOLO et al., 
2005; OLIVEIRA et al., 2007). No óleo essencial foram encontrados vários compostos como $\alpha$-pineno, $p$-menten9-ol, trans-cariofileno, $\beta$-bisaboleno, $\alpha$-humuleno, $\alpha$-santaleno, d-limoneno, óxido de cariofileno, eugenol, mirceno, aromadendreno, $\beta$-selineno e 1,8-cineol (CRAVEIRO et al., 1981; CUELLAR et al., 1984; PINO et al., 2001).

A Azadirachtia indica A. Juss., espécie da família Meliaceae, é conhecida popularmente por Neem (nim) ou Amargosa. Suas propriedades há muito tempo são utilizadas não só em medicina e cosmética, mas também na agricultura, neste último caso como praguicida. Essa planta tem elevado conteúdo de azadiractina, um princípio ativo que tem demonstrado grande eficácia no combate a pragas e doenças que atacam plantas e animais (SCHMUTTERER, 1990).

A resistência ou tolerância aos metabólitos secundários que funcionam como aleloquímico é variável, existindo espécies mais sensíveis que outras, como, por exemplo, Lactuca sativa (alface) e Lycopersicum esculentum (tomate), que são hortaliças sensíveis a esses metabólitos e, por isso, comumente usadas em biotestes em laboratório antes dos aleleoquímicos serem testados em plantas espontâneas (ALVES et al., 2004). Essas espécies possuem, ainda, a vantagem de apresentar a germinação rápida e uniforme e um grau de sensibilidade que as permite expressar resultados a baixas concentrações. Nesse contexto, o presente trabalho teve como objetivo identificar os efeitos alelopáticos de extratos voláteis de óleos essenciais na germinação e no comprimento da raiz de plântulas de tomate.

\section{Material e Métodos}

\section{Área de estudo}

O ensaio foi realizado no Laboratório de Biologia da Universidade Estadual do Piauí (UESPI), localizado na região norte do litoral piauiense, Parnaíba - PI, situado

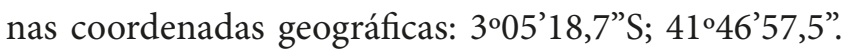
O clima da região é do tipo C1dA'a', caracterizado como subúmido seco, megatérmico, com pequeno excedente hídrico e uma concentração de $29,7 \%$ da evapotranspiração potencial no trimestre outubro, novembro e dezembro, com umidade média relativa do ar de $77,5 \%$, e temperatura média de $29^{\circ} \mathrm{C}$ (INMET, 2018).

\section{Procedimentos de laboratório}

As sementes de tomate, variedade "tomate gaúcho melhorado nova seleção", tratadas com fungicida Captan, na proporção de $20 \mathrm{~g}^{\mathrm{kg}}{ }^{-1}$ de sementes, foram submetidas ao efeito de óleos essenciais de plantas medicinais de colônia (Alpinia zerumbet (Pers.) B. L. Burtt. \& R. M. Sm.), goiaba (Psidium guajava L.) e nim (Azadirachtia indica A. Juss).

Os óleos foram extraídos das folhas de plantas adultas, por arraste a vapor de água, tendo como base o método descrito por Alencar et al. (1990), e, em seguida, acondicionados em frascos escuros e mantidos em refrigerador a $5^{\circ} \mathrm{C}$. Posteriormente, cada óleo foi emulsionado com Tween 80, na proporção 1:1 e dissolvido em água destilada para a obtenção de soluções com concentrações 0,$25 ; 0,50 ; 0,75 ; 1$ e $0,0 \%$ (v/v). Essas concentrações constituíram os tratamentos e, para a concentração de 0,0 , utilizou-se a solução de Tween 80 a $1,0 \% \mathrm{v} / \mathrm{v}$. A verificação do potencial alelopático dos extratos voláteis de cada óleo, nas diversas concentrações, foi realizada por avaliação de germinação, comprimento das raízes e comprimento da parte aérea de plântulas. Para o teste de germinação, quatro repetições de 25 sementes foram semeadas em placas de Petri $(9 \mathrm{~cm}$ de diâmetro), tendo como substrato três folhas de papelfiltro, esterilizados em autoclave.

Logo após a semeadura do tomate, $3 \mathrm{~mL}$ da solução de cada concentração de óleo foram distribuídos em três papéis-filtro. A testemunha foi semeada apenas com água destilada e Tween 80 a 1\%, sendo $3 \mathrm{~mL}$ o volume final. Em seguida, essas placas foram levadas para câmara de germinação, a $25^{\circ} \mathrm{C}$, com fotoperíodo de $8 \mathrm{~h}$ de luz. A umidade do papel foi mantida utilizando a solução sempre que necessário durante o período de incubação.

\section{Análises e procedimentos estatísticos}

Foram avaliados os parâmetros porcentagem de germinação, avaliada no décimo dia após a semeadura, sendo que as sementes foram consideradas germinadas 
com a protrusão da radícula e os resultados foram expressos em porcentagem, Índice de Velocidade de Germinação (IVG), no qual a contagem foi realizada diariamente do $4^{\circ}$ até o $10^{\circ}$ dia após a semeadura, realizando-se os cálculos conforme a metodologia recomendada por Maguire (1962).

O experimento para a determinação do comprimento da radícula e da parte aérea foi instalado de forma semelhante ao da germinação. Após $48 \mathrm{~h}$ da semeadura, foram selecionadas 40 plântulas (quatro repetições de 10 plântulas) com 0,2 cm de comprimento de radícula. Essas plântulas foram transferidas para placas de Petri contendo as soluções referentes aos tratamentos e retornadas à câmara de germinação. Foram avaliados o comprimento da radícula e o comprimento da parte aérea. Essa avaliação procedeu-se após quatro dias de incubação, em que se mediram as radículas e a parte aérea utilizandose uma régua milimétrica, e os resultados médios foram expressos em centímetros por plântula.
O delineamento experimental foi inteiramente casualizado, com quatro repetições por tratamento. Foram realizados testes de normalidade e igualdade de variâncias e posteriormente os dados foram submetidos à análise de variância e, quando os efeitos de tratamentos apresentaram diferença significativa $(\mathrm{p}<0,01)$, as médias foram comparadas por meio do teste de regressão não linear, conforme Ferreira (1996).

\section{Resultados}

$\mathrm{Na}$ avaliação do efeito alelopático de óleos essenciais sobre a germinação de sementes de tomate, foi observada a redução da porcentagem de germinação gradativamente à medida que se aumentou a concentração do óleo essencial de colônia, sendo que o menor percentual (2\%) ocorreu na concentração de $1 \%$ (Tabela 1).

TABELA 1: Efeito alelopático da germinação e do crescimento das plântulas de tomate (Lycopersicon esculentum Miller) submetidas a diferentes concentrações de óleos essenciais de colônia (Alpinia zerumbet (Pers.) B. L. Burtt. \& R. M. Sm., nim (Azadirachtia indica A. Juss) e goiaba (Psidium guajava L.). G\%: percentual de germinação, IVG: Índice de Velocidade de Germinação, $\mathbf{C R}$ : comprimento da radícula, CPA: comprimento da parte aérea.

\begin{tabular}{cccccc}
\hline \multicolumn{2}{c}{ Concentração do óleo (\%) } & G (\%) & IVG (\%) & CR (cm/planta) & CPA (cm/planta) \\
\hline Colônia & & & & & \\
\hline & 0 & $100 \mathrm{a}$ & $24,25 \mathrm{a}$ & $44,5 \mathrm{a}$ & $31,27 \mathrm{a}$ \\
& 0,25 & $98 \mathrm{a}$ & $17,86 \mathrm{a}$ & $25,59 \mathrm{~b}$ & $14,13 \mathrm{~b}$ \\
& 0,5 & $94 \mathrm{a}$ & $17,93 \mathrm{a}$ & $6,55 \mathrm{c}$ & $10,95 \mathrm{c}$ \\
& 0,75 & $88 \mathrm{~b}$ & $11,97 \mathrm{~b}$ & $0 \mathrm{~d}$ & $0 \mathrm{~d}$ \\
\hline Goiaba & $2 \mathrm{c}$ & $0,37 \mathrm{c}$ & $0 \mathrm{~d}$ & $0 \mathrm{~d}$ \\
\hline & & & & $31,27 \mathrm{a}$ \\
& 0 & $100 \mathrm{a}$ & $24,25 \mathrm{a}$ & $44,5 \mathrm{a}$ & $13,78 \mathrm{~b}$ \\
& 0,25 & $100 \mathrm{a}$ & $18,45 \mathrm{~b}$ & $47,68 \mathrm{a}$ & $12,4 \mathrm{~b}$ \\
& 0,5 & $100 \mathrm{a}$ & $19,81 \mathrm{~b}$ & $39,36 \mathrm{~b}$ & $11,65 \mathrm{~b}$ \\
& 0,75 & $97 \mathrm{a}$ & $19,41 \mathrm{~b}$ & $38,9 \mathrm{~b}$ & $11,43 \mathrm{~b}$ \\
\hline 1 & $95 \mathrm{a}$ & $15,37 \mathrm{~b}$ & $29,56 \mathrm{c}$ & $31,27 \mathrm{a}$ \\
& & & & $18,79 \mathrm{~b}$ \\
& $100 \mathrm{a}$ & $24,25 \mathrm{a}$ & $44,5 \mathrm{a}$ & $20,18 \mathrm{~b}$ \\
& 0 & $100 \mathrm{a}$ & $26,23 \mathrm{a}$ & $52,02 \mathrm{a}$ & $18,96 \mathrm{~b}$ \\
& 9,25 & $26,22 \mathrm{a}$ & $52,27 \mathrm{a}$ & $19,86 \mathrm{~b}$ \\
\hline
\end{tabular}

*Letras diferentes representam diferenças significativas em relação às diferentes concentrações de um mesmo óleo essencial e o controle no teste Tukey a 5\% de probabilidade. Os óleos não foram comparados entre si. 
Na tabela 1, observa-se uma redução no percentual de germinação a partir de 0,75\% (88\%) de concentração da solução do óleo de colônia, sendo mais significativo na concentração de $1 \%$ (2\%). Com relação ao Índice de Velocidade de Germinação (IVG), houve um atraso na germinação do tomateiro a partir da concentração de $0,75 \%$ do óleo essencial de colônia, sendo que a velocidade de germinação foi drasticamente reduzida na concentração de $1 \%(0,37)$ em relação ao controle $(24,25)$.

A interferência no comprimento da raiz e da parte aérea foi mais acentuada com o aumento da concentração, sendo que nas sementes submetidas à solução do óleo de colônia a 0,75\% e 1\% de concentração não ocorreu crescimento da raiz e da parte aérea da plântula do tomate (Tabela 1).

Ao avaliar o efeito do óleo de goiaba na germinação de sementes de tomate, não foram encontradas diferenças significativas nas concentrações testadas (Tabela 1). Já para a variável Índice de Velocidade de Germinação (IVG), verificou-se que o óleo essencial de goiaba retardou a germinação das sementes de tomate, proporcionalmente as concentrações utilizadas, sendo que a concentração de $1 \%$ prejudicou com maior intensidade a velocidade de germinação $(15,37)$ (Tabela 1).

Para o Comprimento da Parte Aérea, o óleo essencial de goiaba provocou redução em todas as concentrações, sendo que a concentração de $1 \%$ proporcionou a menor média $(11,43 \mathrm{~cm})$, evidenciando efeitos alelopáticos para esse parâmetro. Em relação ao Comprimento da Parte Aérea, observa-se que ocorreu diferença estatística estre os tratamentos e a testemunha. Entretanto, entre os tratamentos não houve diferença estatística (Tabela 1).

Para as variáveis percentual de germinação, Índice de Velocidade de Germinação e comprimento da raiz da plântula de tomate, não foi verificada diferença significativa entre os tratamentos quando submetidos à solução do óleo de nim (Tabela 1). Já para a variável comprimento da parte aérea da plântula, todas as concentrações do óleo de nim demonstraram efeito inibitório quando comparadas com a testemunha, mas não houve diferença estatística entre as concentrações (Tabela 1).

\section{Discussão}

No processo germinativo, podem penetrar, com a água, algumas substâncias alelopáticas capazes de inibir ou retardar a multiplicação ou crescimento das células, podendo assim retardar a germinação (GONZALEZ et al., 2002), dessa maneira, dados do presente trabalho corroboram os dados do referido autor.

Alves et al. (2004) demonstraram que extratos dos óleos essenciais de canela, alecrim-pimenta, capimcitronela e alfavaca-cravo nas maiores concentrações $0,1 \%$ e $1 \%$ inibiram significativamente a porcentagem de germinação de sementes de alface. Magalhães et al. (2013), avaliando concentrações crescentes de óleo essencial de capim-santo observaram efeito alelopático na germinação e índice de velocidade de germinação de sementes de alface nas concentrações de 0,25 e 0,50\%, ao passo que nas concentrações de 0,75 e $1 \%$ não houve diferença significativa.

Miranda et al. (2015) também demonstraram o potencial alelopático de óleos essenciais de plantas medicinais de capim-limão e alfavaca, os quais provocaram completo impedimento da germinação e vigor de aquênios de alface a partir das concentrações de $0,25 \%$ e $0,12 \%$, respectivamente. Garbim et al. (2015), observaram que sementes de alface sob influência de óleo essencial de eucalipto (Eucalyptus globulus Labill) tiveram a germinação totalmente inibida na concentração 0,3\%.

Araujo et al. (2018) verificaram que extratos aquosos das folhas e cascas do caule de Sesbania virgata (Cav.) Pers em doses crescentes (50, 75 e 100\%) apresentaram interferência na velocidade de germinação de alface. Souza et al. (2017) verificaram que, em doses decrescentes de óleo essencial de Croton nepetaefolius, o IVG, em tomate, foi significativamente reduzido com a concentração de 50\% e 100\%.

De acordo com a Tabela 1, o óleo essencial de colônia nas concentrações de $0,75 \%$ e $1 \%$ inibiu tanto o comprimento da raiz quanto o comprimento da parte 
aérea, havendo escurecimento da radícula, causando a morte, provavelmente pela oxidação e degradação dos tecidos. Evidenciou-se, nas concentrações em questão, a ação de substâncias tóxicas do óleo essencial de colônia, pelo escurecimento e fragilidade das raízes que foram inibidas.

Para Cruz-Ortega et al. (1998), modificações morfológicas são resultantes de ações de fitotoxinas. Hoffmann et al. (2007) ressaltam que o sistema radicular das plantas é o mais sensível à ação de aleloquímicos porque o seu alongamento depende das divisões celulares as quais, se inibidas, comprometem o seu desenvolvimento normal. Alves et al. (2014), testando extratos voláteis de óleos essenciais de C. zeylanicum, $L$. sidoides e C. nardus, verificaram que esses óleos causaram a deterioração total das raízes e morte das plântulas de B. pilosa com a concentração de $0,08 \%$.

Áquila (2000) observou um efeito alelopático mais drástico sobre o desenvolvimento inicial de uma plântula alvo quando comparado à germinação, tendo em vista que o processo germinativo utiliza reservas da própria semente. No entanto, no presente estudo, quando se utilizou óleo essencial de colônia na concentração de $1 \%$, pode-se verificar efeitos tanto sobre a germinação quanto sobre o desenvolvimento das sementes de tomate (comprimento da raiz e comprimento da parte aérea).

De modo diferente aos efeitos tóxicos supramencionados, o óleo essencial de goiaba não inibiu a germinação de sementes de tomate em nenhuma das concentrações testadas. Segundo An et al. (1993), é assumido que os efeitos alelopáticos de um dado aleloquímico, quando em baixa concentração, podem não ser inibitórios para dada espécie receptora ou apresentar efeitos estimulatórios em determinados casos.

Antonelo et al. (2017), testando quatro extratos vegetais de espécies florestais em base aquosa de Pinus elliotti Engelm., Zanthoxylum rhoifolium Lam., Mimosa scabrella Bentham e Ilex paraguariensis St.-Hil., com três diferentes concentrações (100\%, 66,4\% e 33,20\%), verificou não haver potencialidade alelopática dessas concentrações sobre a germinação de sementes de alface. Semelhantemente, Bonfim et al. (2013) notaram que o macerado de funcho (Foeniculum vulgare Mill.) não provocou diferença significativa na porcentagem de germinação e na matéria-seca de plântulas de alface quando submetidas às concentrações de 25, 50, 75 e $100 \%$. Entretanto, o comprimento da radícula e o índice de velocidade de germinação de alface foram influenciados pelas concentrações, havendo redução linear significativa dessas variáveis com o aumento da concentração.

O comprimento da raiz de alface, à concentração de $0,25 \%$ do óleo essencial de goiaba, apresentou comportamento diferenciado dos demais, no qual a média do comprimento radicular $(47,68 \mathrm{~cm})$ foi superior ao controle $(44,5 \mathrm{~cm})$ (Tabela 1$)$, indicando que houve efeitos alelopáticos estimulatórios para essa concentração. Teixeira e Bonfim (2014) também verificaram efeito estimulante do extrato de melissa (Melissa officinalis L.) por infusão sobre o crescimento radicular de plântula de alface.

Observa-se que o óleo essencial de nim não interferiu na germinação das sementes de tomate, em nenhuma das concentrações utilizadas. Dessa forma, é possível inferir que os constituintes voláteis presentes no óleo de nim, até a concentração de $1 \%$, não causam efeitos alelopáticos negativos para as sementes de tomate. Da mesma forma, Souza Filho et al. (2009) obtiveram efeitos inibitórios com o óleo de nim em concentrações acima de $1 \%$ sobre a germinação de sementes de mata-pasto (Senna obtusifolia (L.) Irwing \& Barneby).

Resultados similares foram encontrados por Muller et al. (2017), os quais, avaliando o potencial alelopático de folhas de manga (Mangifera indica) sobre a germinação e desenvolvimento de plântulas de cártamo (Carthamus tinctorius), obtiveram melhores médias do IVG na concentração de $25 \%$ e, com o incremento da dosagem do extrato, foi retardado o índice de velocidade de emergência nas concentrações de 75\% e 100\%.

Ao analisar o comprimento radicular da alface, os tratamentos utilizando o óleo de nim não diferiram estatisticamente do controle, mas houve uma tendência de inibição no crescimento da raiz em relação ao controle 
conforme o aumento progressivo das concentrações utilizadas (Tabela 1). De acordo com Carvalho et al. (2002), o crescimento radicular se justificaria pela presença de algum dos agentes aleloquímicos, estimulando o crescimento e podendo caracterizar um efeito alelopático. Souza Filho et al. (2009) obtiveram resultados diferentes, demonstrando atividade inibitória do óleo de nim na germinação e no desenvolvimento da radícula das plantas daninhas mato pasto (Senna obtusifolia (L.) Irwing \& Barneby) e malícia (Mimosa pudica L.) de maneira mais intensiva na concentração de 3\% do óleo.

Entretanto, para a variável Comprimento da Parte Aérea, observou-se redução dessa variável em todas as concentrações do óleo essencial de nim: 0,25\% (18,79 $\mathrm{cm}), 0,50 \%(20,18 \mathrm{~cm}), 0,75 \%(18,96 \mathrm{~cm})$ e $1 \%(19,86$ $\mathrm{cm})$, se comparado ao tratamento controle $(31,27 \mathrm{~cm})$ (Tabela 1).

A disparidade observada do comprimento da parte aérea sobre o comprimento radicular com o óleo de nim pode ser ocasionada pelas estruturas próprias de cada órgão, ou seja, os aleloquímicos presentes no óleo podem interferir no crescimento da parte aérea das plântulas de tomate. Esses resultados corroboram as afirmações de Áquila et al. (1999), segundo as quais, a ação dos aleloquímicos podem variar conforme o órgão da planta onde atuam, sendo capazes de causar inibições em determinadas regiões e incrementos em outras. Para Seigler (1996), os aleloquímicos podem ter ação seletiva e, além disso, as plantas podem também ser seletivas em suas respostas, tornando difícil a síntese do modo de ação desses compostos.

Os resultados permitem concluir que o óleo essencial de Colônia inibiu a germinação de sementes de tomate na concentração de $1 \%$, bem como reduziu o IVG. A concentração de $0,75 \%$ e $1 \%$ inibiu totalmente o comprimento radicular e o comprimento da parte aérea das plântulas de tomate. Os óleos essenciais de goiaba e de nim não apresentaram redução na germinação em relação às concentrações testadas. O óleo de nim apresentou efeito alelopático inibitório apenas para o crescimento da parte aérea da plântula do tomate.

\section{Referências}

ALENCAR, J. W.; CRAVEIRO, A. A.; MATOS, F. J. A.; MACHADO, M. I. L. Kovats indices simulation in essential oil analysis. Química Nova, São Paulo, v. 3, n. 4, p. 282-284, 1990.

ALMEIDA, E. R. Plantas medicinais brasileiras: conhecimentos populares e científicos. São Paulo: Hermus, 1993. 341 p.

ALMEIDA, F. S. Efeitos alelopáticos de resíduos vegetais. Pesquisa Agropecuária Brasileira, Brasília, v. 26, n. 2, p. 221-236, 1991.

ALVES, M. C. S.; MEDEIROS FILHO, S.; INNECCO, R.; TORRES, S. B. Alelopatia de extratos voláteis na germinação de sementes e no comprimento da raiz de alface. Pesquisa Agropecuária Brasileira, Brasília, v. 39, n. 11, p. 1083-1086, 2004.

ALVES, M. C. S.; MEDEIROS FILHO, S.; MANOEL NETO, A.; BRITO, R. C.; ARAUJO, R. C. Allelopathic effect of essential oils of medicinal plants in Bidens pilosa L. Revista Brasileira de Plantas Medicinais, Botucatu, v. 16, n. 3, p. 731-736, 2014.

AMARAL, F. M. M.; RIBEIRO, M. N. S.; BARBOSA-FILHO, J. M.; REIS, A. S.; NASCIMENTO, F. R. F.; MACEDO, R. O. Plants and chemical constituents with giardicidal activity. Revista Brasileira de Farmacognosia, Curitiba, v. 16, Supl. 0, p. 696-720, 2006.

AN, M.; JOHNSON, I. R.; LOVETTE, J. V. Mathematical modeling of allelopathy: biological response to allelochemical and its interpretation. Journal of Chemical Ecology, Tampa, v. 19, n. 10, p. 2379-2389, 1993.

ANTONELO, F. A.; OTALAKOSKI, J.; CORSI, L.; DOSSENA, S. C.; DIAS, I. C. G.; VIEIRA, F. S.; LIMA, D. M. Potencial alelopático de espécies florestais sobre a germinação de sementes de Lactuca sativa L. In: JORNADA DE PÓS-GRADUAÇÃO E PESQUISA, 14, 2017, Bagé. Resumos... Bagé: Revista da jornada da Pós-Graduação e Pesquisa-Congrega, 2017. Versão eletrônica disponível em: <http://trabalhos.congrega. urcamp.edu.br/index.php/14jpgp/article/view/2454/1295>. ÁQUILA, M. E. A. Efeito alelopático de Ilex paraguariensis A. St. -Hil. na germinação e crescimento inicial de Lactuca sativa L. Iheringia, Porto Alegre, v. 53, n. 23, p. 51-66, 2000.

ÁQUIlA, M. E. A.; UNGARETTI, J. A. C.; MICHELIN, A. Preliminary observation on allelopathic activity in Achyrocline satureoides (Lam) DC. Acta Horticulturae, Leuven, v. 502, n. 1, p. 383-388, 1999.

ARAUJO, E. C. G.; CARDOSO SILVA, T.; LIMA, T. V. Efeitos alelopáticos de Sesbania virgata (cav.) Pers na germinação de sementes de alface. Engenharia na Agricultura, Viçosa, v. 26, n. 2, p. 101-109, 2018.

BARBOSA, J. A.; FERREIRA, S. D.; SALVALAGGIO, A. C.; COSTA, N. V. C.; ECHER, M. M. Allelopathy of aqueous Pachyrhizus erosus L. extracts on Euphorbia heterophylla and Bidens pilosa. Pesquisa Agropecuária Tropical, Goiânia, v. 48, n. 1, p. 59-65, 2018.

BONFIM, P. G.; SOUZA, F. K. F.; GUIMARÃES, S. F.; DORES, R. G. R.; FONSECA, M. C. M.; CASALI, V. W. D. Efeito de extratos aquosos de funcho na germinação e vigor de sementes de alface e salsa. Revista Trópica - Ciências Agrárias e Biológicas, Chapadinha, v. 7, n. 3, p. 218-228, 2013.

CARvalho, G. J.; FOnTANÉTti, A. A.; CANÇADO, C. T. Potencial alelopático do feijão de porco (Canavalia ensiformes) e da mucuna preta (Stilozobium aterrimum) no controle da tiririca 
(Cyperus rotundus). Ciência e Agrotecnologia, Lavras, v. 26, n. 3, p. 647-651, 2002.

COELHO, F. M.; OLIVEIRA, S. G. de; BALIZA, D. P.; CAMPOS, A. N. R. Efeito de extratos de plantas espontâneas na germinação e no crescimento inicial do feijão comum. Revista Brasileira de Agroecologia, Porto Alegre, v. 9, n. 2, p. 185-192, 2014.

CRAVEIRO, A. A.; FERNANDES, A. G.; ANDRADE, C. H. S.; MATOS, F. J. A.; ALENCAR, J. W.; MACHADO, M. I. L. Óleos essenciais de plantas do nordeste. Fortaleza: UFC, 1981. 210 p.

CRUZ-ORTEGA, R.; ANAYA, A. L.; HERNÁNDEZ BAUTISTA, B. E.; LAGUNA HERNÁNDEZ, G. Effects of allelochemical stress produced by Sicyios deppei on seedling root ultrastructure of Phaseolus vulgaris e Curcubita ficifolia. Journal of Chemical Ecology, Lexington, v. 24, n. 12, p. 2039-2057, 1998.

CUELlAR, A. C.; LARA, R. A.; ZAYAS, J. P. Psidium guajava L. Tamizaje fitoquímico y estudio del aceite esencial. Revista Cubana de Farmacia, Havana, v. 18, n. 1, p. 92-99, 1984.

FERREIRA, P. V. Estatística experimental aplicada às ciências agrárias. Maceió: Edufal, 1996. 306 p.

FIORENZA, M.; DOTTO, D. B.; BOLIGON, A. A.; BOLIGON, A. A.; ATHAYDE, M. L.; VESTENA, S. Análise fitoquímica e atividade alelopática de extratos de Eragrostis plana Nees (capimannoni). Iheringia, Porto Alegre, v. 71, n. 2, p. 193-200, 2016.

GARBIM, T. H. S.; ROMANO, E. D. B.; CARNEIRO, S. M. T. P. G.; SOUZA, M. L. V. Efeito do óleo essencial de eucalipto sobre a germinação e o crescimento de rabanete e alface. Revista Saúde e Biologia, Campo Mourão, v. 10, n. 1, p. 52-58, 2015.

GOMES, B. R.; SIQUEIRA-SOARES, R. C.; SANTOS, W. D.; MARCHIOSI, R.; SOARES, A. R.; FERRARESE-FILHO, O. The effects of dopamine on antioxidant enzymes activities and reactive oxygen species levels in soybean roots. Plant Signaling \& Behavior, Austin, v. 9, n. 12, p. 1-6, 2014.

GONDIM, A. N. S.; OLIVEIRA, V. R.; SILVA, L. R.; SILVA, B. A.; CONDE-GARCIA, E. A. Complete atrioventricular block on isolated guinea pig heart induced by na aqueous fraction obtained from Psidium guajava L. leaf. Braz. J. Revista Brasileira de Farmacognosia, Curitiba, v. 16, n. 3, p. 312-316, 2006.

GONZALEZ, H. R.; MEDEROS, D.; SOSA, H. I. Efectos alelopáticos de restos de diferentes espécies de plantas medicinales sobre la albahaca (Ocimum basilicum L.) em condiciones de laboratório. Revista Cubana de Plantas Medicinales, Havana, v. 7, n. 2, p. 67-72, 2002.

HERNÁNDEZ-ARO, M.; HERNÁNDEZ-PÉREZ, R.; GUILLÉNSÁNCHEZ, D.; TORRES-GARCIA, S. Allelopathic influence of residues from Sphagneticola trilobata on weeds and crops. Planta Daninha, Viçosa, v. 33, n. 1, p. 81-90, 2016.

HOFFMANN, C. E. F; NEVES, L. A. S.; BASTOS, C. F.; WALLAU, G. L. Atividade alelopática de Nerium oleander L. e Dieffenbachia picta Schott em sementes de Lactuca sativa L. e Bidens pilosa L. Revista de Ciências Agroveterinárias, Lages, v. 6 , n. 1, p. 11-21, 2007.

INMET - INSTITUTO NACIONAL DE METEOROLOGIA. Normal climatológica. 2018. Disponível em <http://www.inmet. gov.br/portal/index.phb?r=clima/normaisClimatologicas $>$. Acesso em: 01 agosto 2018 .
LARANJA, S. M. R.; BERGAMASCHI, C. M.; SCHOR, N. Evaluation of acute administration of natural products with potential diuretic effects, in humans. Memórias do Instituto Oswaldo Cruz, Rio de Janeiro, v. 86, Supl. 2, p. 237-40, 1991.

LARANJA, S. M. R.; BERGAMASCHI, C. M.; SCHOR, N. Avaliação de três plantas com potencial diurético. Revista Associação Médica Brasileira, São Paulo, v. 38, n. 1, p. 6-13, 1992.

LESSA, B. F. T.; SILVA, M. L. S.; BARRETO, J. H. B.; OLIVEIRA, A. B. Efeitos alelopáticos de extratos aquosos de folhas de Amburana cearensis e Plectranthus barbatus na germinação de Amaranthus deflexus. Revista de Ciências Agrárias, Lisboa, v. 40, n. 1, p. 79-86, 2017.

LORENZI, H.; SOUZA, H. M. Plantas ornamentais no Brasil: arbustivas, herbáceas e trepadeiras. São Paulo: Instituto Plantarum, 2001. 1067 p.

MAGALHÃES, H. M.; AQUINO, C. F.; SOARES, E. P. S.; SANTOS, L. D. T.; LOPES, P. S. N. Ação alelopática de óleos essenciais de alecrim-pimenta e capim-santo na germinação de aquênios de alface. Semina: Ciências Agrárias, Londrina, v. 34, n. 2, p. 485-492, 2013.

MAGUIRE, J. D. Speed of germination-aid in selection and evaluation for seedlig emergence and vigor. Crop Science, Madison, v. 2, n. 1, p. 176-177, 1962.

MATIAS, R.; ROSA, A. C.; OLIVEIRA, A. K. M.; PEREIRA, K. C. L.; RIZZI, E. S.; MACHADO, A. A. Cashew nut shell liquid and formulation: toxicity during the germination of lettuce, tomato seeds and coffee senna and seedling formation. Acta Scientiarum, Maringá, v. 39, n. 4, p. 487-495, 2017.

MIRANDA, C. A. S. F.; CARDOSO, M. G.; CARVALHO, M. L. M.; MACHADO, S. M. F.; GOMES, M. S.; SANTIAGO, J. A.; TEIXEIRA, M. L. Atividade alelopática de óleos essenciais de plantas medicinais na germinação e vigor de aquênios de alface. Semina: Ciências Agrárias, Londrina, v. 36, n. 3, Supl. 1, p. 1783-1798, 2015.

MORENO, F.; PLAZA, G. A.; MAGNITSKIY, S. V. Effect of the seed coats on germination of rubber (Hevea brasiliensis Muell.) seeds. Agronomía Colombiana, Bogotá, v. 24, n. 2, p. 290-295, 2006.

MULLER, F.; SEABRA JÚNIOR, E.; DAL POZZO, D. M.; SANTOS, R. F; SILVEIRA, L. Potencial alelopático de folhas de manga (Mangifera indica) sob a germinação, emergência e desenvolvimento inicial de plantas de cártamo (Carthamus tinctorius L.). Acta Iguazu, Cascavel, v. 6, n. 5, p. 159-165, 2017.

OLIVEIRA, F. Q.; GOBIRA, B.; GUIMARÃES, C.; BATISTA, J.; BARRETO, M.; SOUZA, M. Espécies vegetais indicadas na odontologia. Revista Brasileira de Farmacognosia, Curitiba, v. 17, n. 3, p. 466-476, 2007.

PICCOLO, G.; ROSA, D. M.; MARQUES, D. S.; MAULI, M. M.; FORTES, A. M. T. Efeito alelopático de capim limão e sabugueiro sobre a germinação de guanxuma. Semina: Ciências Agrárias, Londrina, v. 28, n. 3, p. 381-386, 2007.

PINO, J. A.; AGUERO, J.; MARBOT, R.; FUENTES, V. Leaf oil of Psidium guajava L. from Cuba. Journal of Essential Oil Research, Carol Stream, v. 31, n. 1, p. 61-62, 2001.

REZENDE, C. P.; PINTO, J. C.; EVANGELISTA, A. R.; DOS SANTOS, I. P. A. Alelopatia e suas interações na formação e manejo de pastagens. Boletim Agropecuário, Lavras, v. 54, n. 1, p. 1-55, 2003. 
RICE, E. L. Allelopathy. New York: Academic Press, 1984. 422 p. RIZVI, S. J. H.; HAQUE, H.; SINGH, U. K.; RIZVI, V. A discipline called allelopathy. In: RIZVI, S. J. H.; RIZVI, H. (Ed.). Allelopathy - Basic and applied aspects. 1 ed. London: Chapman \& Hall, 1992. p. 1-10.

ROSA, D. M.; FORTES, A. M. T.; PALMA, D.; MARQUES, D. S.; CORSATO, J. M.; LESZCZYNSKI, R.; MAULI, M. M. Efeito dos extratos de tabaco, leucena e sabugueiro sobre a germinação de Pnicum maximum Jaqc. Revista Brasileira de Biociências, Porto Alegre, v. 5, n. 2, p. 444-446, 2007.

SCHMUTTERER, H. Proprieties and potential of natural pesticides from the neem tree. Annual Review Entomology, Palo Alto, v. 35, n. 3, p. 271-298, 1990.

SEIGLER, D. S. Chemistry and mechanisms of allelopathy interactions. Agronomy Journal, Madison, v. 88, n. 6, p. 876-885, 1996.

SILVEIRA, B. D.; HOSOKAWA, R. T.; NOGUEIRA, A. C.; WEBER V. P. Atividade alelopática e Araucaria angustifolia (Bertol.) Kuntze na germinação e crescimento inicial de Lactuca sativa L. Ciência Florestal, Santa Maria, v. 24, n. 1, p. 79-85, 2014.

SOUZA, G. S.; BONILLA, O. H.; CHAVES, B. E.; LUCENA, E. M. P.; SILVA, C. S. Potencial alelopático de seis espécies do gênero Croton L. na germinação de alface e tomate. Iheringia, Série Botânica, Porto Alegre, v. 72, n. 2, p. 155-160, 2017.
SOUZA, S. A. M.; STEIN, V. C.; CATTELAN, L. V.; BOBROWSKI, V. L.; ROCHA, B. H. G. Utilização de sementes de alface e de rúcula como ensaios biológicos para a avaliação do efeito de extratos aquosos de plantas medicinais. Revista de Biologias e Ciências da Terra, Campina Grande, v. 5, n. 1, p. 1-8, 2005.

SOUZA, L. S.; VELINI, E. D.; MARTINS, D.; ROSOLEM, C. A. Efeito alelopático de capim-braquiária (Brachiaria decumbens) sobre o crescimento inicial de sete espécies de plantas cultivadas. Planta Daninha, Viçosa, v. 24, n. 4, p. 657-668, 2006.

SOUZA FILHO, A. P. S.; CUNHA, R. L.; VASCONCELOS, M. A. M. Efeito inibitório do óleo de Azadirachta indica A. Juss. Sobre plantas daninhas. Revista Ciências Agrárias, Belém, v. 52, n. 1, p. 79-86, 2009.

SOUZA FILHO, A. P. S.; DUARTE, M. L. R. Atividade alelopática do filtrado de cultura produzido por Fusarium solani. Planta Daninha, Viçosa, v. 25, n. 1, p. 227-230, 2007.

TEIXEIRA, D. A.; BONIM, F. P. G. Efeito alelopático de melissa, capim-cidreira, lavanda e alecrim na germinação e vigor de sementes de alface. Biotemas, Florianópolis, v. 27, n. 4, p. 37-43, 2014.

VENDRUSCOLO, G. S.; RATES, S. M. K.; MENTZ, L. A. Dados químicos e farmacológicos sobre as plantas utilizadas como medicinais pela comunidade do bairro Ponta Grossa, Porto Alegre, Rio Grande do Sul. Revista Brasileira de Farmacognosia, Curitiba, v. 15, n. 4, p. 361-372, 2005. 